\title{
A INFLUENNCIA DAS REDES SOCIAIS NA INOVAÇÃO: \\ um estudo de caso em uma incubada do Centro Incubador Tecnológico - CIT/FUNDETEC
}

\section{1- Jaiane Aparecida Pereira*}

Mestre em Administração pela Universidade Estadual de Maringá (UEM), Brasil.

Professor Colaborador da Universidade Estadual de Maringá (UEM), Brasil.

profjaiane@yahoo.com.br

http://lattes.cnpq.br/8453684332126511

\section{2- Maurício Reinert}

Doutor em Administração pela Fundação Getúlio Vargas (EAESP/FGV), Brasil. Professor do Programa de Pós-Graduação em Administração (PPA/UEM), Brasil. mrnascimento@uem.br

http://lattes.cnpq.br/5978684124962276

\begin{tabular}{l} 
Diego Maganhotto Coraiola - Editor Geral \\
\multicolumn{1}{c}{ Editor responsável pela submissão: } \\
Emerson Maccari. \\
Artigo analisado via processo de revisão duplo cego (Double-blind). \\
Recebido em: $14 / 03 / 2013$ \\
provado em: $27 / 05 / 2013$ \\
ltima Alteração: $16 / 05 / 2013$
\end{tabular}

* Contato Principal:Rua Osvaldo Cruz, 699. Zona 7, Maringá - PR, Brasil. CEP: 876020-200. 


\title{
A INFLUÊNCIA DAS REDES SOCIAIS NA INOVAÇÃO: UM ESTUDO DE CASO EM UMA INCUBADA DO CENTRO INCUBADOR TECNOLÓGICO - CIT/FUNDETEC
}

\section{RESUMO}

O presente trabalho tem como objetivo geral analisar como os processos de formação e evolução das redes sociais influenciaram a inovação de uma empresa incubada do Centro Incubador Tecnológico CIT/FUNDETEC, desde a fundação até o ano de 2011. Para alcançar o objetivo proposto, o referencial abordou discussões sobre redes sociais, condições iniciais de fundação, processos empreendedores de pós-fundação e inovação. Foi realizada uma pesquisa qualitativo-descritiva, utilizando-se do estudo de caso como desenho de pesquisa, com recorte longitudinal. A coleta de dados ocorreu por meio de entrevista semiestruturada com o fundador da empresa incubada. Para análise dos dados optou-se pela análise de conteúdo com auxílio do software Atlas.ti. Os resultados demonstram a importância das redes tanto na formação quanto na evolução da empresa, provendo recursos e informações que auxiliam na criação e no desenvolvimento da inovação. $O$ estudo evidencia também a importância da reputação do fundador para adquirir legitimidade à empresa e os benefícios da incubadora no seu período inicial de incubação.

Palavras-chave: Inovação. Redes Sociais. Incubadas.

SOCIAL NETWORK INFLUENCE ON INNOVATION: A CASE STUDYIN ONE OF THE INCUBATED COMPANY UNDER TECHNOLOGICALINCUBATORCENTER-CIT/FUNDETEC

\begin{abstract}
This study aimsat analyzinghow the formation and evolution processes of social networksinfluence theinnovationin one of the incubated company under Technologicallncubator CenterCIT/FUNDETECfrom foundationto the year of 2011.To achieve this propose, theoretical framework discussed social networks, initial foundation conditions, post-founding entrepreneurial processes and innovation. A qualitativedescriptivestudy was conducted using thecase study asresearch design, withlongitudinalcutting. We constructed data collection using semi-structured interviews with founder incubated company. For data analysis we based on the content analysis technique using Atlas.ti software. The results evidence both networks importance in formation and evolution company processes, providing resourcesand information toassist on innovation creation anddevelopment. The studyalso shows the reputation importanceof the founder company to acquirelegitimacyand benefitsof the incubatorin itsinitial incubation period.
\end{abstract}

Keywords: Innovation. Social network. Incubated company. 


\section{Introdução}

A inovação passou a ser vista como um processo chave para sobrevivência, desenvolvimento e melhoria das organizações. Sua importância é bastante discutida nos tempos atuais, tendo em vista as crescentes demandas por melhor desempenho de produtos e serviços, visando atender o aumento das exigências da sociedade (Vale, Wilkinson, \& Amâncio, 2008). Para entender essas necessidades e desenvolver novos produtos, processos ou a melhoria dos produtos e processos existentes, é preciso haver a troca de informações que possibilitem um maior conhecimento do que o mercado necessita e, consequentemente, do que a empresa pretende oferecer a ele.

Atualmente, as redes de relacionamento adquiriram um lugar de destaque nos processos de desenvolvimento da inovação (Stuart \&Sorenson, 2005; Quandt, 2012), sendo que os tipos de relacionamentos entre as pessoas, a intensidade e a frequência com que eles acontecem apresentam-se como influenciadores do intercâmbio de ideias, favorecendo a geração de conhecimento e a identificação de oportunidades (Reagans\&MCEvily, 2003; Elfring\&Hulsink, 2007). A partir da importância das redes sociais como um fator de impulso à inovação, algumas redes formadas por empreendedores e pesquisadores estão sendo criadas. Em 1993, devido à necessidade de incentivo ao empreendedorismo e à inovação, foi criada a Fundação para o Desenvolvimento Científico e Tecnológico [FUNDETEC], uma autarquia pública do município de Cascavel-PR, visando desenvolver o progresso econômico e social da região (http://www.fundetec.org.br>, recuperado em 27, fevereiro, 2011). Desta forma, o centro incubador, juntamente com a rede formada pela fundação, aparece como uma fomentadora do processo de inovação, contribuindo para o desenvolvimento do Estado e da sua região.

Para tentar entender o processo de inovação dentro do ambiente da incubadora, uma alternativa é estudar as redes de relacionamento por meio da formação dos laços das empresas. Elfring e Hulsink (2007) investigaram padrões específicos de desenvolvimento de laços na formação e evolução das redes dos empreendedores, identificando duas condições que influenciam na empresa ao longo do tempo: (1) as condições iniciais de fundação e (2) os processos empreendedores de pós-fundação, ou seja, os contatos e informações adquiridas pelo empreendedor na formação da sua organização, bem como as redes adquiridas no decorrer de suas atividades, podem direcionar o futuro da organização.

Pressupõe-se, então, que os tipos de laços e padrões de redes de relacionamento do empreendedor no momento da criação da organização vão influenciar diretamente no tipo de inovação que a empresa desenvolve. Como as redes também evoluem na medida em que o empreendedor atua no mercado, podendo formar novos laços ou romper laços antigos. Essa mudança poderia acarretar outras influências no desenvolvimento da inovação na organização. Desta forma, parte-se da premissa de que a formação e a evolução das redes da empresa influenciam no processo de surgimento e aperfeiçoamento da inovação.

Tendo em vista o exposto, apresenta-se o seguinte problema: Como os processos de formação e evolução das redes sociais influenciaram a inovação de uma incubada do Centro Incubador Tecnológico [CIT/FUNDETEC] desde a fundação até o ano de 2011? Visando responder a essa indagação, o presente trabalho tem como objetivo principal analisar como os processos de formação e evolução das redes sociais influenciaram a inovação de uma empresa incubada do CIT/FUNDETEC desde a fundação até o ano de 2011 . De modo específico, o artigo propõe a identificação de condições iniciais de fundação e processos empreendedores de pós-fundação para verificar como essas condições influenciaram a rede social da incubada, por meio das características relacionais das suas redes e, por fim, analisar a influência da rede social na inovação da empresa.

Para alcançar o objetivo proposto, o artigo apresenta, primeiramente, o referencial teórico, abordando discussões sobre as redes sociais e a inovação. Em seguida, apresenta-se a metodologia utilizada. Posteriormente, são analisados os dados sobre a empresa em questão e, por fim, destacam-se algumas considerações finais.

\section{Sociologia Econômica}

A discussão sobre sociologia econômica vem crescendo, sobretudo a partir do início dos anos de 1980 (Lévesque, 2007). Swedberg (2004) afirma que a sociologia econômica estuda o setor econômico na sociedade, a maneira pela qual os fenômenos econômicos influenciam a sociedade e o modo pelo qual a sociedade os influencia, enfatizando que os fenômenos econômicos são sociais por natureza. Sua ênfase foi na produção de alternativas sociológicas ao mainstream da teoria econômica (Swedberg, Himmelstrand, \&Brulin, 1987).

Ao unir análises sociológicas e econômicas, a sociologia econômica visa obter explicações mais abrangentes dos fatos socioeconômicos do que a teoria econômica, sem, contudo, recusá-la (Steiner, 2006). Neste contexto, pode-se supor que toda ação econômica está inserida num contexto social e para estudá-la é preciso considerar este fato, visando entendê-la de maneira mais completa. Para Granovetter (1990), a sociologia econômica apoia-se em duas proposições sociológicas fundamentais: em primeiro lugar, a ação é sempre socialmente localizada e não pode ser explicada, fazendo-se referência apenas aos motivos individuais que possam tê-la ensejado; depois, as instituições sociais não surgem automaticamente, elas são construídas socialmente.

Nota-se que a sociologia econômica procura complementar a teoria econômica, com uma visão mais ampla e socialmente imersa. Granovetter (1985) ainda argumenta que a sociologia econômica se preocupa com 
uma das questões clássicas da teoria social: como os comportamentos e instituições são afetados pelas relações sociais. Desta maneira, o autor discute que as atividades econômicas estão estruturalmente imersas em redes de relações pessoais. Essaersão social é chamada "social embeddedness".

O conceito "embeddedness", proposto por Granovetter (1985), surge do argumento de que os comportamentos e as instituições ao serem analisados são tão compelidos pelas contínuas relações sociais que interpretá-los como sendo elementos independentes pode representar um grave mal-entendido. O conceito foi inicialmente formulado por Karl Polanyi (embedded) e posteriormente recuperado a partir dos seus escritos e reconstruído por Mark Granovetter (Krippneret al., 2004). Polanyi (2000) notou que os sistemas econômicos estão imersos em relações sociais, sendo que a distribuição dos bens materiais é assegurada por motivos nãoeconômicos.

Partindo do pressuposto de que as atividades são imersas, contemporaneamente, a sociologia econômica aproveita-se do desenvolvimento da análise de redes sociais (Steiner, 2006). Assim, torna-se necessário entender a formação de uma rede social para, posteriormente, analisar as interações dos atores que são membros dessa rede. Na próxima seção foram expostas visões para melhor compreensão das redes sociais, visando orientar o desenvolvimento do estudo.

\section{Redes Sociais}

A análise de rede social tem sido um elemento explorado de várias formas para entender e explicar o comportamento das pessoas, principalmente dentro de um grupo. Diversos estudos abordaram as redes sociais para explicar diferentes fenômenos: os trabalhos de Granovetter (1985) buscaram compreender até que ponto a ação econômica está imersa nas estruturas das relações sociais, ou como a estrutura social afeta os resultados econômicos; já outros trabalhos, como os de Ahuja (2000), Reagans e McEvily (2003) e AutantBernard, Fadairo e Massard (2013) exploram a geração, transferência e difusão da inovação e do conhecimento dentro de uma rede.

Uma rede social consiste de um conjunto finito de atores e a relação definida entre eles (Wasserman\&Faust, 1994; Burt, 2004), ou seja, a interação existente dentro de uma estrutura, dentro de um grupo. Para Castilla, Hwang, Granovetter e Granovetter (2000, p. 219), as redes sociais podem ser definidas como "um conjunto de nós ou atores (pessoas ou organizações) ligados por relações sociais ou laços de um tipo específico. Um laço ou relação entre dois atores tem força e conteúdo". A força do laço é uma combinação da quantidade de tempo, intensidade emocional, intimidade e serviços recíprocos que o caracterizam, podendo ser fraco, forte ou ausente (Granovetter, 1973). O conteúdo pode incluir informação, conselho ou amizade, interesses comuns ou associação, e tipicamente algum nível de confiança (Castillaet al., 2000).

O aspecto relacional das redes sociais aponta a característica dos relacionamentos entre as pessoas através dos seus laços, que podem ser mais fortes e frequentes ou mais fracos e menos frequentes. Dentre os estudos pioneiros sobre essa temática destacam-se os trabalhos de Mark Granovetter: TheStrengthofWeakTies, publicado em 1973; e Getting a Job, publicado em 1974, nos quais o autor introduziu a discussão sobre o papel das redes no mercado de trabalho, bem como na promoção e acesso a oportunidades existentes na estrutura social e econômica (Martes, Loureiro, Abramovay, Serva, \& Serafim, 2007). Em Getting a Job, Granovetter identificou que no mercado de trabalho os que possuem mais laços fracos (vínculos de amizade) têm acesso a informações mais relevantes e mais eficientes do que os chamados laços fortes (vínculos de família), sendo que os laços fracos são mais úteis na obtenção de um emprego (Steiner, 2006). Essa característica foi apontada por Granovetter (1973) como "a força dos laços fracos", pois as novas informações e ideias são mais difundidas de modo eficiente por meio de laços fracos, pois são mais prováveis de unir membros de grupos diferentes.

Nota-se que o tipo de rede em que uma organização está imersa define as oportunidades potencialmente disponíveis, e tanto sua posição na estrutura da rede bem como seu tipo de relação dentro dessa rede definem o acesso a oportunidades (Uzzi, 1996; Baldi\& Vieira, 2006). Os laços fracos, também denominados laços amplos, caracterizados pelas conexões que não estão tão imersas, previnem o isolamento da rede abrindo espaço a novas possibilidades (Uzzi, 1996). Por outro lado, os laços fortes, caracterizados por indivíduos que estão envolvidos socialmente, como as relações entre amigos próximos e parentes, comportariam mais informações redundantes e, por isso, não apresentariam as vantagens dos laços fracos. Entretanto apontam outras vantagens como a confiança, legitimidade e feedback confiável (Elfring\&Hulsink, 2007).

A confiança e a reputação são indicadas por empreendedores como retornos relevantes na interação em redes (Paiva \& Almeida, 2010). A pesquisa de campo mostra que a confiança atua como um mecanismo de governança de relacionamentos imersos, pois facilita a troca de recursos e informações que são cruciais para um alto desempenho, mas são difíceis de avaliar e transferir através de laços de mercado (Uzzi, 1996). A confiança é pessoal e predispõe uma pessoa a interpretar favoravelmente as intenções e ações de outra, sendo importante porque aumenta o acesso de uma organização a recursos e reforça sua capacidade de adaptação a problemas imprevistos (Uzzi, 1996). É importante frisar que a confiança é difícil de alcançar por meio de laços amplos, sendo necessários laços imersos para gerá-la.

Apesar dos benefícios dos laços imersos, eles também apresentam alguns pontos negativos como: (1) a perda de uma rede essencial para a organização, (2) arranjos institucionais que racionalizam o mercado ou rompem laços sociais e (3) a superimersão (overembeddedness), que é caracterizada por uma profunda 
imersão, ou seja, as organizações estão tão conectadas que podem reduzir o fluxo externo de novas informações (Uzzi, 1997).

Diante da capacidade dos estudos sobre a força e a intensidade dos laços, percebe-se que vem crescendo as discussões de como as redes sociais possibilitam o acesso a novas informações e, consequentemente, à inovação. Vários estudos associam as redes sociais com a inovação, pois a inovação é um processo social que envolve a comunicação e o compartilhamento de ideias entre as pessoas (Tidd, Bessant, \&Pavitt, 2008). Para evidenciar essa relação, o próximo tópico apresenta alguns estudos que associam inovação às redes sociais.

\section{Inovação e Redes Sociais}

Quando se fala em inovação, a primeira impressão é de algo que ainda não existe. Segundo Rogers (2003, p. 12), “uma inovação é uma idéia, prática ou objeto que é percebido como novo por um indivíduo ou outra unidade de adoção". Desta maneira, algo que é utilizado por uma pessoa, grupo ou organização, pode se apresentar como novo para outra. Portanto, torna-se complexo caracterizar o conceito de inovação.

Segundo Andreassi (2007), as inovações podem ser: de produto, quando a empresa introduz um novo produto ou serviço na sua linha de atuação; de processo, quando são introduzidos novos processos produtivos; de gestão, com a introdução de novos processos administrativos; e de modelo de negócio, quando a empresa modifica a essência do seu negócio. Deste modo, quando a inovação de produto e processos é acompanhada de nova tecnologia, ocorrem inovações tecnológicas (Andreassi, 2007).

A literatura sobre inovação tem distinguido entre inovações radicais e incrementais (Moreira \& Queiroz, 2007). A inovação radical é aquela que produz mudanças fundamentais na organização, representando o abandono de práticas existentes e o desenvolvimento de rotinas completamente novas (Johannessen, Olsen, \&Lumpkin, 2001). A inovação incremental procura melhorar o que já existe, sendo caracterizada por adaptações das rotinas existentes, ajustando-se as normas e valores da organização de maneira menos perturbadora (Moreira \& Queiroz, 2007).

Entre os tipos de inovação, há diferentes graus de novidade indo desde melhorias incrementais menores até mudanças realmente radicais, transformando a forma como as pessoas veem ou usam as coisas (Tiddet al., 2008). Para Johannessenet al. (2001), a questão da novidade deve ser seguida da pergunta "novo para quem?", ou seja, é preciso determinar a unidade de análise para operacionalizar a distinção entre radical e incremental. Os autores visualizam um continuum de unidades de adoção paralelo ao continuum radical e incremental, assim quanto mais ampla a unidade de adoção, mais provável que o impacto da inovação seja radical (Johannessenet al., 2001). Dentro desse aspecto, as inovações tecnológicas são geralmente as que mais se aproximam de uma inovação radical, acarretando mudanças profundas para um produto, setor ou empresa. A indústria da tecnologia da informação, na maioria das economias desenvolvidas, é um setor dinâmico em que novas tecnologias podem rapidamente ficar obsoletas e sua aplicação cria ou revoluciona mercados e demandas (Elfring\&Hulsink, 2007).

Os graus de inovação, radical e incremental, demandam diferentes tipos de redes sociais (Elfring\&Hulsink, 2003b). As inovações radicais perturbam as condições econômicas e exigem mudanças no contexto empresarial, estando ligadas à exploração (exploration) e destruição de competência. A exploration é caracterizada pela busca por novos conhecimentos, o uso de tecnologias desconhecidas e a criação de produtos com demanda desconhecida (Greve, 2007; Saari\&Kallio, 2011). Por outro lado, as inovações incrementais são menos perturbadoras e mais ligadas à exploração (exploitation) no sentido de melhoria das competências existentes, na qual o empreendedor pode construir sobre competências já existentes (Elfring\&Hulsink, 2003b). A exploitation baseia-se no uso e aperfeiçoamento dos atuais conhecimentos, tecnologias e produtos (Greve, 2007). Sendo assim, verifica-se que, para explorationhá uma necessidade maior de laços fracos, diferentemente da exploitation, que requer mais laços fortes. Entretanto, ambas são atividades fundamentais para a organização. Por conseguinte, discute-se que o mix de laços mais vantajoso para a organização depende de alguns fatores. Uma estrutura ótima de redes depende dos objetivos dos membros da rede, pois tanto os laços diretos (conexão direta entre dois indivíduos) quanto os laços indiretos (conexão indireta de dois indivíduos através de um mediador) influenciam na inovação dessas empresas, sendo que o impacto dos laços indiretos é moderado pelos laços diretos da organização (Ahuja, 2000).

Apesar das inúmeras pesquisas sobre redes e inovação, os estudos sobre os antecedentes do desenvolvimento de redes e sua influência na inovação ainda são limitados (Elfring\&Hulsink, 2007). Por esse motivo, Elfring e Hulsink (2007) pesquisaram como as redes influenciam a inovação, tanto nas condições iniciais de fundação de uma empresa, quanto nos processos empreendedores de pós-fundação. Os próximos tópicos apresentam discussões sobre esses assuntos.

\section{Condições Iniciais de Fundação}

As condições iniciais de fundação incluem: a condição inicial da rede; o tipo de inovação introduzida pela empresa; e a forma e origem dos recursos (Elfring\&Hulsink 2003b; 2007). As condições iniciais de fundação são formadas pelas diferentes condições que o empreendedor possui quando decide fundar uma organização, estando inserido em algumas redes de relacionamentos que podem influenciar e direcionar o futuro da empresa. Stinchcombe (1965) foi o primeiro a estudar como a condição social afeta o grau de motivação para criação de novas organizações, observando que organizações fundadas em tempos distintos apresentam 
diferentes estruturas sociais. Essa hipótese, conhecida hoje como imprinting organizacional, chama a atenção para essas condições iniciais de fundação (Johnson, 2007).

A teoria de imprinting foi abordada de várias perspectivas diferentes, como as condições históricas no desenvolvimento das redes das organizações (Marquis, 2003); a importância do impacto do empreendedor no processo de desenvolvimento da organização (Johnson, 2007); e a perspectiva do empreendedor e do ambiente organizacional (Boeker, 1988; Eisenhardt\&Schoonhoven, 1990). Neste sentido, apresentam-se diferentes aspectos das condições iniciais de fundação e seus impactos duradouros.

Elfring e Hulsink (2007) identificaram três aspectos: (1) a condição inicial da rede, (2) o tipo de inovação introduzida pela empresa e (3) a forma e origem dos recursos. Sobre o primeiro aspecto, a condição inicial da rede, Elfring e Hulsink (2007) afirmam que deve-se ao fato do empreendedor ser um insiderou um outsider. É considerado insideraquele empreendedor que tem contatos com o pessoal central da indústria; um outsider é aquele que não possui conexões com a indústria (Elfring\&Hulsink, 2007). Kadushin (2002) aponta que relacionamentos com insiderssão mais densos e têm mais suporte e confiança do que com outsiders.

A segunda condição identificada por Elfring e Hulsink (2007) é o tipo de inovação introduzida pela empresa, distinguindo entre inovação radical, que é mais ligada à exploração e capacidade de destruição; e inovação incremental, menos perturbadora e vinculada a um reforço de algo já existente. As empresas baseadas em inovação radical exigem uma combinação de laços fortes e fracos diferentes daquelas que trabalham com inovação incremental (Elfring\&Hulsink, 2003b).

Por fim, a terceira condição inicial da rede é a forma e origem dos recursos, ou seja, como o empreendedor adquiriu os recursos necessários para a fundação da organização. Johnson (2007) revela que os recursos disponíveis em um contexto particular de fundação exercem uma enorme influência sobre o caráter de uma nova organização, persistindo, além da fase de fundação, como a disponibilidade de recursos tecnológicos, econômicos, políticos e culturais.

Ao discutir a importância das condições iniciais de fundação, nota-se que elas podem persistir ao longo do tempo; entretanto, podem também se modificar devido aos processos empreendedores de pós-fundação, que são apresentados no próximo tópico.

\section{Processos Empreendedores de Pós-Fundação}

Os processos empreendedores de pós-fundação são: a identificação de oportunidades; a captação de recursos; e a legitimidade (Elfring\&Hulsink, 2003a, 2003b, 2007). Sobre a capacidade de descobrir oportunidades, Elfring e Hulsink (2003a, p. 7) defendem que "uma importante fonte de novas ideias e oportunidades lucrativas podem ser as redes, em que o empreendedor está mais ou menos participando ativamente". Uma oportunidade empreendedora é uma situação na qual as mudanças na tecnologia ou em condições políticas, sociais e demográficas geram o potencial de criar algo diferente (Ardichvili, Cardozo, \& Ray, 2003), sendo seu reconhecimento uma etapa chave do processo empreendedor (Shane\&Venkataraman, 2000).

Para Shane e Venkataraman (2000), a identificação de oportunidades envolve a descoberta, reconhecimento e exploração de uma fonte de oportunidade que orienta o futuro de uma empresa. Ardichviliet al. (2003) desenvolveram uma teoria do processo de identificação de oportunidade a partir de três fatores: (1) a personalidade do empreendedor, (2) as redes sociais e (3) o conhecimento prévio, sendo esses fatores descritos como um alerta (alertness) ao empreendedor, ou seja, uma condição necessária para o sucesso do reconhecimento, desenvolvimento e avaliação de uma oportunidade.

O conhecimento prévio é um fator que auxilia o empreendedor no reconhecimento de oportunidades, pois nem todas as pessoas estão propícias a ter uma visão de negócio, mas ter um conhecimento anterior ou uma informação privilegiada pode oferecer uma vantagem na criação da empresa (Shane, 2000). Sanz-Velasco (2006) constata que o conhecimento prévio tem sido mostrado empiricamente como influente para quem descobre uma oportunidade, sendo que ele distingue três áreas de conhecimento prévio, que são: (1) o mercado, (2) maneiras de servi-lo e (3) problemas dos clientes. A partir desses três elementos, o empreendedor pode perceber uma oportunidade e então buscar recursos para poder explorá-la.

A exploração de uma oportunidade depende da obtenção de recursos por parte do empreendedor. $A$ capacidade de garantir recursos é o segundo processo de pós-fundação. Elfring e Hulsink (2003b) discutem que proporcionar acesso a recursos é uma importante contribuição da rede, pois raramente os empreendedores possuem todo o recurso necessário e obter recursos é uma tarefa muito difícil, principalmente no começo, sendo que um suporte próximo, como laços de família, tanto provendo recursos financeiros quanto capital humano, podem promover certa estabilidade nas fases iniciais.

O próximo desafio para o empreendedor, que é o terceiro processo de pós-fundação identificado, é a obtenção de legitimidade para garantir sua permanência no mercado. Elfring e Hulsink (2003b) enfatizam que algumas empresas são aceitas por causa da reputação do empreendedor e, consequentemente, não precisam estabelecer laços para transmitir legitimidade, enquanto outras necessitarão de tais laços para alcançá-la. Uma boa reputação corporativa pode ser crucial para o desenvolvimento de um empreendimento de sucesso (Goldberg, Cohen, \&Fiegenbaum, 2003). Por esse motivo, a legitimidade, ou falta dela, é uma questão importante para novos empreendedores (Aldrich\&Fiol, 1994), ou para empreendedores no contexto de mudança, pois mudança organizacional requer legitimidade (Erkama\&Vaara, 2010). “A legitimidade é uma 
percepção generalizada ou pressuposto de que os recursos em uma entidade são desejáveis, correto ou apropriado dentro de algum sistema socialmente construído de normas, valores, crenças e definições" (Suchman, 1995, p. 574).

De maneira geral, tanto a legitimidade como os outros processos empreendedores de pós-fundação também podem ser influenciados pelas redes sociais e vice-versa. A descoberta de oportunidades depende de informações relevantes sobre mercados, formas de atendê-los e aos clientes; na aquisição de recursos, o empreendedor precisa se mobilizar para garanti-los; e quanto a ganhar legitimidade, o empreendedor também precisa mobilizar a sua rede para superar as barreiras da legitimidade (Elfring\&Hulsink, 2003b).

Diante do intenso fluxo de troca de informações e influências das empresas e o ambiente, tanto nos processos iniciais de fundação quanto nos processos empreendedores de pós-fundação, pode-se pressupor uma conexão entre as redes sociais e a inovação. A literatura permite inferir que as redes sociais são recursos importantes para a inovação, pois mantêm canais e fluxos de informação nos quais confiança e respeito aproximam os atores. Estes, por sua vez, compartilham informações modificando ou ampliando seu conhecimento (Tomaél, Alcará, \& Chiara, 2005).

A importância da inovação em empresas de base tecnológica é evidente, tanto que normalmente ela é um atributo solicitado para a entrada na incubadora, porém cada incubadora estabelece normas e procedimentos diferentes quanto a essa temática. Com a proposta de estudo da formação e evolução das redes sociais e sua influência sobre a inovação dentro do ambiente das incubadoras tecnológicas, é possível uma análise longitudinal em um curto período de tempo. Para entender o processo de incubação, o próximo tópico estabelece o conceito de incubadoras e incubadas, visando esclarecer alguns procedimentos exigidos para o ingresso nesse ambiente.

\section{Incubadoras e Empresas Incubadas}

Diante da importância da troca de informações para o desenvolvimento de produtos ou serviços inovadores, têm surgido vários mecanismos de incentivo a empreendedores, como a intensificação da relação universidade-empresa por meio de incubadoras (Bruneel, Ratinho, Clarysse, \&Groen, 2012). As incubadoras são "organizações-mãe" que, em geral, envolvem uma instituição acadêmica ou uma grande empresa bem estabelecida (Bessant\&Tidd, 2009; Serra, Serra, Ferreira, \&Fiates, 2011). A incubadora é um local especialmente criado para abrigar empresas e oferecer uma estrutura que estimule, agilize ou favoreça a transferência de resultados de pesquisa para atividades produtivas (http://www.anprotec.org.br, recuperado em 15, maio, 2012).

As empresas incubadas ou empresas residentes são organizações que desenvolvem produtos ou serviços inovadores, estão abrigadas em uma incubadora e passam por processo de seleção para isso, recebendo apoio técnico, gerencial e financeiro de uma rede de instituições constituídas especialmente para criar e acelerar o desenvolvimento de pequenos negócios (ANPROTEC \& SEBRAE, 2002). Antes de serem empresas incubadas, os projetos podem passar por um período chamado de pré-incubação, que é um conjunto de atividades que visam estimular o empreendedorismo e preparar projetos que tenham potencial de negócios em um curto período de tempo - de seis meses a um ano -, sendo que, nessa fase, é dada grande ênfase ao plano de negócios, pesquisa de mercado e a preparação dos empreendedores sobre gestão de negócios. Essa fase também pode ser chamada de hotel de projetos, hotel de ideias, hotel tecnológico, etc. (ANPROTEC \&SEBRAE, 2002). Após o período de incubação, a empresa recebe o nome de graduada, que é a organização que passou pelo processo de incubação e alcançou desenvolvimento suficiente para ser habilitada a sair da incubadora. Todavia essa empresa pode continuar mantendo vínculo com a incubadora na condição de associada (ANPROTEC \& SEBRAE, 2002).

A incubadora que abriga empresas de base tecnológica é uma estrutura que prioriza o desenvolvimento de empresas onde a tecnologia dos produtos, processos ou serviços representam alto valor agregado (http://www.mct.gov.br/index.php/content/view/5228.html, recuperado em 22, março. 2012). Por esse motivo, as incubadoras surgem como fomentadoras do processo de inovação, podendo ser um instrumento de propagação de informações através de suas redes sociais (Nascimento et al., 2011; Binder\&Maccari, 2013 ).

Atualmente, existem cerca de 400 incubadoras espalhadas por todo o país, com 6.300 empreendimentos inovadores, que, juntos, geram aproximadamente 33 mil postos de trabalho (http://www.anprotec.org.br, recuperado em 15, maio, 2012). No Paraná, existem mais de 30 incubadoras, com parcerias no Brasil e por toda América Latina (http://www. reparte.org.br, recuperado em 15, maio, 2012).

Sendo assim, devido à importância do contexto das redes sociais e sua influência sobre a inovação e sendo as incubadoras ambientes especialmente criados para desenvolver a integração e estimular a inovação, o referencial abordado buscou esclarecimentos e o desenvolvimento do trabalho proposto.

\section{Procedimentos Metodológicos}

A presente pesquisa caracteriza-se como de natureza qualitativa do tipo descritiva (Denzin\&Linconl, 1994), pois descreve o processo de inovação de uma empresa incubada a partir das suas redes sociais. Utilizouse o estudo de caso como desenho de pesquisa (Godoy, 2006), buscando compreender profundamente como as 
redes sociais, tanto nas condições iniciais de fundação, quanto nos processos empreendedores de pós-fundação influenciaram na inovação da empresa.

Foi pesquisada uma empresa incubada do CIT/FUNDETEC, da cidade de Cascavel-PR. Foi escolhida uma empresa em estágio final de incubação, para tentar entender a influência da rede sobre a inovação em todo o período em que ela permaneceu incubada. A escolha da incubada justifica-se ainda pelo fato da inovação ser pouco pesquisada em pequenas empresas, principalmente aquelas situadas em cidades do interior.

Foram coletados e analisados dados primários, construídos por meio de entrevistas semiestruturadas (Fontanta\& Frey, 1994) com o fundador da empresa. A incubada é constituída por dois sócios, no entanto, foi entrevistado o sócio gestor da organização, que é responsável pelas decisões estratégicas da empresa. A sócia realiza funções mais operacionais. Também foram coletados dados secundários por meio do website da incubada e documentos internos para auxiliar na análise.

A pesquisa apresenta um recorte longitudinal (Richardson, 2008). Desta forma, foram feitas duas coletas de dados num intervalo de sete meses com o gestor da empresa incubada, as quais foram suficientes para obter informações e verificar se houve alguma alteração nas redes de relacionamentos e na inovação da empresa. Essa verificação foi possível tendo em vista o tempo de incubação das empresas que dura, em média, dois anos, por isso o intervalo proposto representa mais de um quarto do seu período de incubação. A primeira coleta de dados ocorreu em setembro de 2010 com o intuito de obter dados referentes à empresa desde sua fundação até aquela data (T1), com duração de, aproximadamente, 50 minutos. A segunda entrevista ocorreu em abril de 2011 com o objetivo de verificar se houve alguma mudança na rede e na inovação da empresa (T2), com cerca de 30 minutos.

A condução da primeira entrevista foi efetuada da seguinte forma: primeiro buscou-se investigar o processo de incubação, visando descrever como foi a entrada na incubadora, quais os benefícios alcançados através da incubadora e quais os problemas da incubadora na visão do gestor da incubada. Depois foram analisadas as categorias e subcategorias identificadas a partir da literatura. Na categoria redes sociais, observou-se as redes antes da incubação e as redes após a incubação. Quanto à categoria condições iniciais de fundação, foram utilizadas as subcategorias identificadas na literatura: a condição inicial da rede; o tipo de inovação introduzida pela empresa; e a forma e origem dos recursos. Do mesmo modo, na categoria processos empreendedores de fundação, foram analisadas as subcategorias: identificação de oportunidades; captação de recursos; e legitimidade. Por fim, com relação à categoria inovação, foi identificado o grau de inovação dos produtos e serviços ofertados pela empresa e se a empresa possuía patentes. Na segunda entrevista procurouse descobrir se houve mudanças nas redes sociais e na inovação da empresa.

As entrevistas foram analisadas de acordo com a técnica de análise de conteúdo (Bardin, 1977), buscando identificar a presença de informações relacionadas a cada categoria. Para auxiliar na realização dessas análises foi utilizado o software Atlas/ti(Bandeira-de-Mello, 2006), visando otimizar a codificação das informações coletadas a partir da entrevista e categorizá-las, para posterior interpretação.

As entrevistas foram gravadas, posteriormente transcritas e depois apresentadas ao participante para observação de consonância do que foi informado com o descrito (Creswell, 2007), utilizando-se de protocolos (Cone \& Foster, 2006), visando dar validade à pesquisa.

\section{Apresentação do Caso e Análise dos Resultados}

A empresa em questão foi constituída em 1997 com o objetivo de produzir chás, ervas aromáticas e ervas para chimarrão, devido à demanda existente na região. É uma empresa familiar, na qual o casal forma a sociedade. Ambos são farmacêuticos e, antes de formar essa empresa, já possuíam uma farmácia de manipulação. A empresa possui três funcionários diretos. Segundo o sócio fundador, os motivos que levaram a procura pela incubadora foi o fato de não estar conseguindo obter sucesso com a segunda empresa. Eles desejavam fabricar novos produtos e expandir o campo de atuação e viram a necessidade de buscar parcerias para isso.

Ela não estava atingindo assim um mercado satisfatório e aí nós verificamos que precisaríamos diferenciar a empresa e o produto, e sozinho é difícil, então eu creio que em 2005 nós conhecemos a FUNDETEC e eu decidi incubar a empresa [ ...] nós fomos procurar a incubadora para melhorar e para diversificar o nosso rol de produtos.

Portanto, a empresa apresentou o projeto de uma indústria para fabricação de alimentos funcionais, sendo aprovada para incubação em 25 de agosto de 2005. Embora já tenha passado do período de incubação, a empresa fez a renegociação do contrato e continua incubada principalmente por se tratar de uma indústria e ter uma grande necessidade do espaço físico. Atualmente, a empresa está construindo sua nova sede fora da incubadora, no entanto não tem previsão para mudança.

A partir da necessidade de orientação para a expansão e melhoria da empresa, o primeiro contato com a incubadora ocorreu devido à divulgação da fundação em âmbito municipal. A FUNDETEC existe desde 1993 e seu nome está institucionalizado na região. Três anos depois ela foi ampliada com a criação do parque tecnológico, o que resultou numa ampla divulgação em âmbito municipal. “Eu ouvi falar que é uma empresa municipal, e fornecia subsídios, apoio de ferramentas para o crescimento e desenvolvimento do empresário, então foi por isso que nós buscamos". Para a entrada na incubadora, o entrevistado relata que foi feito um 
plano de negócios assessorado pelo SEBRAE, o qual apresentava um produto inovador, um alimento funcional. O plano foi apresentado a uma comissão para análise de viabilidade, como exige o regimento interno da instituição. O respondente frisa que o projeto foi “submetido a uma banca examinadora da própria instituição e das universidades que participam com ela e a partir dessa aprovação é que foi nos dada então a possibilidade de trabalharmos junto com a FUNDETEC".

Com a entrada na incubadora, o fundador relata que foram feitas conquistas bastante tangíveis. Além do espaço físico, houve subsídio para participação em uma feira, que resultou na finalização da ideia do produto e a participação em cursos e palestras.

Na época nós tínhamos a ideia de criar um alimento funcional diferenciado em forma de fibra, nós tínhamos um conhecimento, mas nós não tínhamos toda a ideia formada e logo no início que nós digamos fomos aceitos na FUNDETEC, nós tivemos oportunidade de participar de uma feira internacional de alimentos em São Paulo, [ ...] e essa participação foi muito importante para a criação do nosso produto e essa feira em especial foi toda ela bancada pela FUNDETEC, a nossa viagem, a nossa estadia.

A participação na feira ocorreu porque a incubadora faz uma busca de eventos que podem auxiliar no desenvolvimento das incubadas.

Existe na FUNDETEC o setor que apoia as empresas incubadas, e então na época existia um funcionário e ele fez essa busca do que poderia ser útil [...] ele nos apresentou essa oportunidade de irmos até a feira, nós verificamos que realmente era interessante.

Além da feira, outro evento citado pelo empreendedor foi um curso sobre tecnologia e inovação, que proporcionou uma nova visão do assunto.

A possibilidade de participar de um curso de tecnologia e inovação e isso de uma certa forma, atuou beneficamente na visão da empresa, de procurar criar produtos que realmente diferenciam a empresa para colocá-la no mercado [ ...] foi uma visão que nós adquirimos, logicamente que nós pagamos por esse curso, mas foi um curso que também foi viabilizado via FUNDETEC, e isso nós fizemos e hoje temos esse conhecimento para poder aplicar na empresa e criarmos novos produtos.

Ainda que existam benefícios, como salientados, é importante ressaltar dois problemas visualizados pelo entrevistado na incubadora: o descompasso entre empresa pública e privada e a falta de auxílio na parte de comercialização do produto. Em primeiro lugar, foi frisada a questão do descompasso entre empresas de naturezas diferentes e o processo burocrático das organizações públicas,

porque o compasso de empresa privada e empresa pública é muito diferente, os tempos são diferentes, as urgências são diferentes e a própria natureza é diferente [ ...] as necessidades que são urgentes, pela própria burocracia não são resolvidas a tempo e aí se perde a oportunidade.

O mesmo problema também aflige a questão da pesquisa e desenvolvimento de novos produtos em instituições públicas, pois a linguagem entre as empresas e a universidade ou centros de pesquisa também acontece em tempos distintos.

Eles não conseguem perceber a tua necessidade e você por uma ansiedade que você tem de colocar o produto no mercado, também não tem tempo, essa paciência de esperar todo esse tempo de um projeto de mestrado, que dura aí dois anos [ ...] então para a empresa dois anos é muita coisa, um produto inovador tem que tá ali em seis meses, você tem que pegar a ideia e tem que executar essa ideia e quando você vai para a universidade e quando você vai para um órgão público, que depende de licitação, de aprovação, existe uma série de coisas que não está diretamente direcionada a uma ação do diretor que está lá na FUNDETEC, ele depende de uma aprovação, isso trava o processo.

Outro problema enfrentado pela incubada, que também pode ser caracterizado como uma lacuna da incubadora, foi a falta de experiência dos sócios na área de gestão. Eles não obtiveram apoio e orientação da incubadora quanto ao desenvolvimento da parte de comercialização dos produtos, não houve preocupação com o acesso ao mercado. O entrevistado alegou que,

por nós sermos profissionais da área de produção, farmacêuticos e não sermos expert na área de comercialização, então faltou essa parte, muitas vezes nós mesmos não procurarmos satisfazermos essa nossa deficiência e também a FUNDETEC, houve uma lacuna, em que essa parte de comercialização, essa parte de colocar o reconhecimento da empresa no mercado é ainda um gargalo.

Enfim, nota-se que a empresa foi beneficiada com a entrada na incubadora, apesar dos problemas percebidos pelo empreendedor, como o descompasso entre empresa pública e privada e a falta de suporte para comercialização dos produtos, a incubada obteve benefícios como o espaço físico, a participação em uma feira internacional e a participação em cursos e palestras. Por mais que a empresa ainda não tenha atingido todos os seus objetivos, ela continua crescendo e se desenvolvendo. A incubadora efetuou um papel importante nesse processo, principalmente mediando contatos que possibilitaram a finalização do desenvolvimento do produto, como vem sendo discutido na literatura (Stuart \&Sorenson, 2005). A seguir, são apresentadas as categorias analisadas na empresa. 


\subsection{Redes Sociais da Empresa}

As redes sociais da empresa são formadas, inicialmente, pela família. Por ser uma empresa constituída por um casal, os laços fortes forneceram um impulso inicial para a criação do empreendimento. Os sócios são formados no mesmo ramo, o farmacêutico, por esse motivo e também por possuírem outra empresa na cidade, têm muitos contatos com profissionais da área de saúde, como farmacêuticos, médicos e nutricionistas. Esses contatos ocasionaram discussões que possibilitaram o desenvolvimento da ideia de criar um alimento funcional. A busca pelo centro incubador se deu principalmente em virtude da necessidade de buscar informações, formar novos laços, buscar novas redes que possibilitassem acesso a recursos diferenciados, como enfatizados: “nós sentimos aí a necessidade de procurar mais informações, necessidade de conhecer novas formas de crescimento, fora do nosso meio familiar e profissional, e foi aí que nós procuramos a FUNDETEC".

Por ser um órgão público, o entrevistado reitera que a incubadora oferece acesso a algumas instituições de pesquisa e órgãos de fomento, atuando como uma ponte que conecta a empresa às redes dessas organizações: "é uma porta, ela facilita você a entrar em contato com outras instituições [...] você não está sozinho, como a rede, a parceria é interessante, então a parceria com a FUNDETEC nos trouxe benefícios". Através do ingresso na incubadora, a empresa estreitou contatos com órgãos como o SEBRAE e universidades. Com relação ao SEBRAE, o respondente cita que ele "está muito próximo da FUNDETEC e nós também usamos bastante o serviço do SEBRAE". Sobre as universidades parceiras, ele observa que "a pesquisa é importante, nós fizemos hoje também convênios com universidades, convênios de pesquisa, de cooperação técnicocientífica [ ...] e isso tem mostrado ambientes favoráveis para a criação de novos produtos".

O empreendedor acredita que o nome da fundação a qual pertence a incubadora pode ser usado como um respaldo, pois pressupõe o desenvolvimento tecnológico e a inovação, o que pode auxiliar a empresa na obtenção de legitimidade. As empresas, para serem incubadas, precisam atender a alguns pré-requisitos da incubadora, como, por exemplo, a busca por melhorias e inovação, gerando confiança para os clientes. Os produtos devem focar o benefício à comunidade, por isso o respondente afirma que

a empresa para estar dentro da FUNDETEC ela tem que cumprir algumas condições de aceitabilidade pela própria FUNDETEC [...] porque quer queira ou não a FUNDETEC realmente está também colocando o nome dela junto com a empresa, e aí existe uma série de condições mínimas para que essa empresa esteja lá, então nós usando o nome da FUNDETEC já podemos colocar para o consumidor que é uma empresa que está buscando seriedade, certificação, bons produtos, isto é a tônica da FUNDETEC.

Nota-se que o nome da fundação repassa confiança para a incubada, parece haver uma troca de informações entre a incubadora e a empresa, pois o respondente alega que as necessidades são reportadas ao órgão da incubadora que apoia as empresas, como frisado na citação "eu diria que tem uma relação de confiança entre a empresa e a incubadora".

Com relação às redes dentro da incubadora, observa-se que os relacionamentos entre a incubada pesquisada e as outras incubadas é mínimo. O respondente revela que existe um ambiente de colaboração entre as incubadas, todavia o seu contato maior ocorre somente com uma incubada que presta serviços para sua empresa, mas, mesmo assim, o relacionamento é de fornecedor para cliente. Não existe troca de informações sobre as empresas e seus produtos ou serviços, "nós, por termos essa questão de alimentos, algumas vezes (a empresa parceira) precisou de um insumo que tínhamos na época, nós fornecemos [...] essas questões assim de trocas são comuns, não existe nenhuma concorrência dentro do ambiente e da incubadora".

De modo geral, percebe-se que as redes de relacionamentos da empresa são formadas pela família, profissionais da área de atuação, clientes e fornecedores. Quando necessita de informações voltadas à inovação, a empresa costuma recorrer aos clientes. Segundo o entrevistado, "os clientes são boas fontes de possibilidades de criação de novos produtos, a necessidade do mercado". A empresa também está procurando por novas formas de comercialização do produto, que é citada como uma de suas deficiências.

No segundo momento da entrevista (T2), o respondente informou que continua com os mesmos contatos citados na primeira entrevista, porém surgiu um contato com uma nova empresa, que está fazendo a logística e distribuição dos seus produtos. A busca pela parceria com o distribuidor foi realizada sem a colaboração da incubadora. O empreendedor havia dito na primeira entrevista que a parte de comercialização dos produtos estava deficiente, portanto procurou no mercado por uma empresa especializada em distribuição de alimentos no pequeno, médio e grande varejo para suprir suas necessidades. Além dessa parceria, que aos olhos do empreendedor está sendo benéfica, a incubada decidiu estar aberta a novas parcerias para distribuição, divulgando no website da empresa e através dos clientes e fornecedores que aceitam propostas para distribuição de outras organizações.

Observa-se que a mudança ocorrida na rede da empresa desde a sua fundação ocorreu devido à entrada na incubadora, que possibilitou o contato com novos fornecedores. Nos últimos sete meses, houve uma mudança na rede, o novo distribuidor. Com esse novo contato, o empreendedor acredita que, apesar da divulgação estar apenas começando, a parceria apresenta grandes perspectivas de aumento de vendas. Ademais, nota-se que o entrevistado mantém os mesmos contatos que possuía no início do empreendimento, em sua maioria composto por laços fortes. No próximo tópico foram investigadas as condições iniciais de fundação da empresa. 


\subsection{Condições Iniciais de Fundação}

Para a formação da empresa, na condição inicial da rede, o empreendedor contou com a família na própria materialização do empreendimento, pois sua esposa é sócia da empresa; e dos contatos com profissionais do seu ramo de atuação, de onde vieram informações sobre as necessidades dos clientes: “a inovação surgiu quando nós tínhamos um cliente precisando desse produto, o nutricionista fornecendo um caminho de como chegar a esse produto e nós como farmacêuticos a escolha desses insumos para materializar".

A motivação para iniciar a empresa surgiu da experiência dos sócios como farmacêuticos em uma farmácia de manipulação da família. Trabalhando com chás e ervas, ele observou a necessidade dos clientes por produtos que regulem a função intestinal, por isso decidiu começar a pesquisar sobre alimentos funcionais:

a própria profissão, nós somos farmacêuticos, trabalhamos na área de medicamentos e também surgiu essa possibilidade de nós trabalharmos com alimentos funcionais, alimentos em si, e aí houve então a intenção de nós criarmos uma indústria para poder assim materializar um desejo nosso de produzir alimentos de boa qualidade.

O empreendedor revela-se um insider, conforme discutido por Elfring e Hulsink (2007), pois tem contatos com pessoas do ramo de atuação. É importante destacar que a personalidade do empreendedor parece também ter influenciado a criação e o desenvolvimento da empresa. Ele afirma reconhecer os problemas da empresa e está sempre em busca de soluções, “nós não estamos assim de forma alguma abalados, nós reconhecemos os benefícios da FUNDETEC e nós somos persistentes, nós estamos caminhando, buscando o nosso espaço". A empresa está no mercado há 13 anos e possui uma predisposição a mudanças e novas parcerias, como por exemplo, no caso citado: "existe um interesse de uma possível importação e a nossa possibilidade de exportação de produtos, mas não se concretizou [...] fizemos o protocolo, colocamos a nossa intenção, mas não tivemos o contato".

Com relação à inovação introduzida pela empresa, observa-se que ela é caracterizada como incremental, pois consiste da melhoria de um produto já existente no mercado. O alimento funcional produzido procurou combinações diferenciadas que trouxessem um benefício maior para seus usuários, o produto apresentava ainda uma segmentação diferenciada, podendo ser utilizado por várias faixas etárias. Segundo o empreendedor, o produto pode ser “utilizado por diversos segmentos, diversas faixas etárias da população, desde crianças a partir de dois anos de idade até pessoas idosas podem utilizar esse produto, então ele tem uma faixa etária muito grande para ser aplicado".

O respondente ainda reitera a importância da inovação incremental para a empresa.

As inovações que nós colocamos são inovações complementares, são inovações, nós vamos incrementando, nós vamos melhorando, nós vamos adaptando, é (sic) situações que fazem com que esse produto seja melhor aproveitado e melhor visto pela clientela, então hoje são ainda inovações incrementais, mas são importantes para a empresa.

Os recursos usados para a abertura da empresa foram o capital próprio. Segundo o empreendedor, a estrutura da outra empresa da família serviu de base para o novo empreendimento, bem como o trabalho dos sócios. O respondente frisa que na parte administrativa da empresa não teve apoio, talvez até por desconhecimento de algumas fontes de recursos. Entretanto, a empresa mostra-se cautelosa quanto a financiamentos, pois pensa que alguns créditos são inviáveis e podem comprometer toda a estrutura da empresa. No próximo tópico foram investigados os processos empreendedores de pós-fundação da empresa.

\subsection{Processos Empreendedores de Pós-Fundação}

Como a empresa já existia anteriormente, a própria incubação se deu através da identificação de uma oportunidade de crescimento, pois o empreendedor sentiu a necessidade de buscar contatos fora da sua rede familiar e profissional. Depois do desenvolvimento do produto inicial, foram criados outros desenvolvidos com base na mesma fórmula. Identifica-se que as oportunidades de criação de novos produtos desenvolvidos por esta empresa foram baseadas no conhecimento prévio que o empreendedor possuía e nas redes sociais profissionais.

Após a incubação, a empresa identificou ainda uma nova oportunidade, a prestação de serviços industriais. A indústria detém registro de alimentos junto à vigilância sanitária, inscrito na ANVISA (Agência Nacional de Vigilância Sanitária), portanto pode industrializar alguns alimentos de outras marcas para que sejam comercializadom pelo proprietário do produto, como exemplificado pelo entrevistado:

por exemplo se um distribuidor ou um empresário queira (sic) explorar um nome comercial e um determinado alimento que nós tenhamos o registro então se faz esse contrato, se faz uma parceria, nós produzimos exclusivamente para ele, para que ele explore então dentro da região dele, aonde nós combinarmos [ ...] ele não precisa fazer a indústria para produzir esse produto, em forma de parcerias nós poderemos prestar essa parte de industrialização para ele e ele dedica-se então todo o seu tempo à comercialização.

Na segunda entrevista (T2), o empreendedor relatou que foi buscar parcerias com uma empresa para comercializar seus produtos. Esse era o maior problema citado na primeira entrevista e agora parece ter sido sanado, pois a empresa parceira é um grande distribuidor de alimentos no varejo e está presente em cinco 
estados brasileiros, possuindo sete unidades de distribuição e atuando em oitocentos e cinquenta e oito municípios. Essa parceria se mostra como uma oportunidade de crescimento para a empresa.

Hoje nós já temos um mercado definido, aonde nós vamos colocar o nosso produto né e temos também a logística de como vai ser distribuído esse produto, isso vai dar um horizonte muito bom para nossa empresa, porque nós não nos preocupamos nessa parte de logística e apenas agora estamos concentrados na parte de divulgação do nosso produto, aonde a gente quer colocar, então fica muito mais fácil.

A empresa possui uma linha de produtos já registrados e através desta empresa parceira que começou a fazer a distribuição e a logística, eles pretendem expandir seus campos de atuação.

Com relação à captação de recursos, no segundo momento da pesquisa (T2), constatou-se que a empresa ainda continua com seus projetos "engavetados", não colocando em prática aqueles que foram relatados na primeira coleta de dados. Observa-se que a empresa prefere crescer vagarosamente, mas não fazer grandes empréstimos. Com essa política conservadora de captação de recursos, eles tentaram vários financiamentos, mas não finalizaram o empréstimo. Segundo o empreendedor, os recursos não foram aceitos "por decisão nossa mesmo da diretoria por entendermos que não eram ainda as taxas adequadas". Eles fizeram alguns projetos para adquirir financiamentos, pois existem verbas para produtos inovadores, entretanto há uma grande dificuldade de acesso a esses créditos. Na visão do respondente, a dificuldade para conseguir créditos mais acessíveis ocorre por dois motivos: primeiro por causa dos procedimentos burocráticos para preenchimento dos editais, depois pela grande concorrência para alcançar esses créditos, que ocorrem em âmbito nacional. Todavia, a partir da parceria feita com a empresa de logística e distribuição, a empresa espera retomar seus projetos e buscar novos investimentos: "nós estamos tendo assim perspectivas de bons negócios".

Por fim, sobre a questão da legitimidade, o empreendedor acredita que a empresa ainda não possui um reconhecimento de mercado. Ele afirma que o apoio recebido da incubadora foi muito bom, mas a parte de colocação do produto no mercado ficou em segundo plano, o que atrapalhou a comercialização do produto e, consequentemente, a distribuição e o reconhecimento. O empreendedor alega que o fato de possuir apoio de um órgão governamental municipal é sempre bem visto, pois facilita a abertura do mercado, porém é apenas uma ferramenta, um caminho, mas não é um selo de garantia de sucesso.

Na segunda entrevista (T2), o empreendedor argumentou que, com a mudança no sistema de distribuição dos produtos, as perspectivas de mercado estão aumentando. Apesar de entender que esse processo é longo e contínuo, ele se mostra confiante: “estamos divulgando nessa área, está sendo bem aceito, mas é um trabalho que está iniciando agora e eu não tenho como te mensurar a questão de se vai dar o resultado esperado ou não, mas me parece bastante promissor".

Embora a empresa não tenha obtido ainda um reconhecimento de mercado, percebe-se que a reputação do fundador apresenta-se como um aspecto positivo para a aceitação da empresa, como discutido por alguns autores como Elfring e Hulsink (2003b). Este fato deve-se, principalmente, pelo trabalho que é realizado na primeira empresa da família, que está no mercado há dezessete anos. Dentro da incubadora, o empreendedor parece também ter bons contatos, tendo em vista a renegociação do processo de incubação, o que permite a empresa estar incubada por um tempo maior do que o acordado inicialmente. A seguir, discute-se a inovação na empresa.

\subsection{Inovação na Empresa}

O processo de criação do produto para incubação ocorreu através da influência das redes profissionais do empreendedor, como discutido no tipo de inovação apresentado pela empresa. Contudo, para finalizar a criação do produto foi necessária a busca por informações fora da rede da empresa, sendo a incubadora importante nesse aspecto, pois proporcionou à empresa a participação em uma feira que ajudou no desenvolvimento do processo criativo.

A partir do primeiro produto, a empresa entendeu a necessidade de possuir um comportamento voltado à pesquisa e à inovação para desenvolver produtos diferenciados, "nós não ficamos só produzindo o que outras indústrias produzem". O produto, alvo da incubação, possuía um diferencial em relação aos similares quando foi lançado, todavia os produtos do ramo de alimentos funcionais possuem um ciclo de vida pequeno, o que exige do empreendedor a necessidade de constante atualização:

quando nós criamos esse produto, realmente ele tinha esse diferencial de apresentar não só a questão da fibra do movimento do peristaltismo, mas também a vantagem de oferecer um alimento prebiótico, onde as bactérias do intestino pudessem se reproduzir com esse alimento, então era um diferencial na época em comparação com outros que existiam, não existia produtos, hoje já existe produtos nesse sentido, mas quando nós criamos a nossa visão estava um passo na frente.

O empreendedor observa que a empresa hoje pesquisa, desenvolve e industrializa alimentos, através dos contatos que possui com universidades: "nós temos um convênio de tecnologia e cooperação técnico-científica com a UNIOESTE firmado, nós estamos na FUNDETEC também é um órgão, é uma instituição de pesquisa", além de possuir estagiários de outras universidades trabalhando na indústria. 
A partir dessas parcerias o empreendedor cita que existe um projeto inovador, no qual pretende utilizar um produto da biodiversidade brasileira aplicado em um alimento funcional para enriquecimento, que está aguardando financiamento. Com esse projeto a empresa pretende agregar valor às commodities para começar a exportar seus produtos industrializados, como é citado pelo entrevistado:

a empresa procura agregar valores às commodities, então nós estamos querendo transformar commodities em produtos de alto valor agregado e aí fazer inclusive exportações que é um dos objetivos (da empresa), é colocar o produto extraído daqui, produtos que sejam característicos do Brasil colocados fora do Brasil, mas não como commodities, colocar o produto já elaborado, processado e de uma maneira em que nós tenhamos um valor agregado nesse produto muito maior do que se nós fossemos exportá-lo in natura.

Com relação à patente, o empreendedor revela que os projetos da empresa têm possibilidade de gerar patente do processo de produção e a empresa vem trabalhando para isso, porém atualmente existe apenas um registro de marcas.

A Figura 1 resume as informações sobre a empresa.

\begin{tabular}{|l|l|}
\hline Entrada na incubadora & $25 / 08 / 2005$ \\
\hline Benefícios alcançados & Espaço físico; Participação em feira; Cursos e palestras \\
\hline Problemas enfrentados & $\begin{array}{l}\text { Descompasso entre empresa pública e privada; Falta de auxílio na } \\
\text { comercialização }\end{array}$ \\
\hline Busca por informações & Clientes; Universidades \\
\hline Condição inicial da rede & $\begin{array}{l}\text { Família (esposa); Profissionais da área (farmacêuticos, médicos, } \\
\text { nutricionistas); Clientes e Fornecedores da primeira empresa }\end{array}$ \\
\hline Tipo de inovação proposta & Incremental \\
\hline Forma e origem dos recursos & Capital próprio; Mão de obra dos sócios \\
\hline Identificação de oportunidades & $\begin{array}{l}\text { Processo de incubação; Prestação de serviços industriais; Parceria para } \\
\text { comercialização }\end{array}$ \\
\hline Captação de recursos & Não \\
\hline Legitimidade & Legitimidade do fundador \\
\hline Mudança na rede & Novos contatos profissionais \\
\hline Mudança na inovação & $\begin{array}{l}\text { Novos produtos desenvolvidos com base no primeiro, também } \\
\text { caracterizados como inovações incrementais }\end{array}$ \\
\hline Patentes & Não, apenas registro de marcas \\
\hline
\end{tabular}

Figura 1 - Resumo das informações sobre a empresa

Fonte: Elaborado pelos autores com base nos dados da pesquisa

Sendo assim, pode-se afirmar que a empresa propõe inovações incrementais de forma constante, devido aos diversos produtos registrados desde sua fundação. Este fato mostra-se condizente com as suas redes de relacionamentos que são, em sua maioria, formadas por laços fortes, por meio da família e dos contatos profissionais, conforme discutido por alguns autores como Granovetter (1973) e Elfring e Hulsink (2007).

\section{Considerações Finais}

Retomando a questão inicial, a presente pesquisa buscou responder a seguinte problemática: Como os processos de formação e evolução das redes sociais influenciaram a inovação de uma incubada do Centro Incubador Tecnológico - CIT/FUNDETEC -, desde a fundação até o ano de 2011? De acordo com a premissa levantada, pode-se considerar que tanto a formação da rede quanto a evolução influenciaram no processo de inovação da incubada. Por esse motivo, faz-se necessária a discussão de quatro questões teóricas relevantes que foram levantadas a partir do problema estudado.

Em primeiro lugar, evidencia-se que as redes dos sócios foram importantes para a criação e o desenvolvimento da inovação proposta, como vêm sendo discutidos na literatura por alguns autores (Granovetter, 1973; Stuart \&Sorenson, 2005), pois a ideia da criação do produto foi influenciada pela necessidade dos clientes, a partir da troca de informações com a sócia da empresa e com profissionais do ramo de atuação, como outros farmacêuticos, médicos e nutricionistas. Após a incubação, houve a participação em uma feira, possibilitando novos contatos com diferentes fornecedores, contribuindo, então, na finalização do desenvolvimento do produto.

O segundo fator a ser destacado está relacionado aos tipos de laços da empresa e sua relação com a inovação. De acordo com alguns autores, os laços fracos estariam mais ligados à inovação radical e os laços fortes à inovação incremental (Granovetter, 1973; Uzzi, 1997). No caso da incubada investigada, o resultado fortalece a teoria, pois a empresa possui muitos contatos no ramo de atuação devido à formação e experiência dos sócios. Isso influenciou no desenvolvimento da inovação, caracterizada como incremental.

A terceira discussão refere-se à importância dos laços fortes no início do empreendimento (Uzzi, 1996; Elfring\&Hulsink, 2007). Observa-se na empresa que o suporte da família foi fundamental, principalmente no acesso a recursos para constituição do capital inicial. A primeira empresa da família serviu de base para o novo empreendimento, fornecendo o espaço físico e os recursos financeiros. A mão de obra dos sócios, que são casados, também teve importante papel nesse período. 
A influência das redes sociais na inovação: um estudo de caso em uma incubada do Centro Incubador Tecnológico - CIT/FUNDETEC

O quarto ponto importante que foi constatado é a relevância da reputação do fundador para adquirir legitimidade à empresa (Elfring\&Hulsink, 2003b; Goldberg, Cohen, \&Fiegenbaum, 2003). Nota-se que o fundador possui muitos contatos no ramo de atuação, devido ao tempo em que está no mercado, e também possui contatos dentro da incubadora. Apesar de ainda não ter alcançado legitimidade no mercado para a incubada, ele é respeitado pelo trabalho que vem realizando ao longo dos anos na primeira empresa, o que aumenta as chances de sucesso da incubada e de aceitação dos seus produtos.

Além dos aspectos teóricos apontados, foi possível também a compreensão de duas evidências importantes que contribuem de maneira prática com o assunto abordado. A primeira contribuição prática da pesquisa está relacionada ao importante papel da incubadora nos primeiros anos da empresa. Percebe-se que a incubadora foi mais atuante nos primeiros anos da incubada, que a cada ano passa a depender menos da incubadora, estando menos ligada à rede da incubadora e mais conectada ao mercado.

O segundo ponto de destaque no trabalho é o uso do nome da fundação pela incubada e não o nome da incubadora. A fundação está institucionalizada na cidade e região, no entanto a incubadora não é conhecida. Em nenhum momento o respondente cita o "CIT/FUNDETEC" ou o "centro incubador da FUNDETEC", ou mesmo a "incubadora"; ele diz apenas a "FUNDETEC". Isso colabora para a disseminação do nome da fundação, porém não divulga o trabalho da incubadora.

Enfim, apesar das contribuições apresentadas, é importante ressaltar algumas limitações metodológicas e práticas que surgiram no decorrer da pesquisa. Com relação à metodologia, a limitação refere-se ao recorte longitudinal. A coleta de dados foi realizada com um período de apenas sete meses da primeira entrevista (T1) para a segunda (T2). Apesar de haver pouca variação neste espaço de tempo, os dados foram suficientes para contribuir com o tema proposto. A limitação prática está ligada à impossibilidade de entrevistar a sócia da empresa que não trabalha diretamente na incubadora e possui outras ocupações, o que pode ter ocultado informações importantes para as conclusões da pesquisa em questão.

Finalmente, sugere-se para pesquisas futuras um período mais longo de observação das redes sociais em empresas incubadas e o acompanhamento de empresas graduadas para entender a dinâmica da formação e evolução dos laços sociais. Indica-se ainda o uso de pesquisas quantitativas a partir dos dados levantados nesta pesquisa, para tentar evidenciar a influência das redes sobre a inovação de modo mais amplo. Também recomenda-se uma análise comparativa via estudo de casos múltiplos com empresas em setores distintos, na mesma incubadora e com tempo aproximado de incubação.

\section{Referências}

Ahuja, G. (2000). Collaboration networks, structural holes and innovation: a longitudinal study. Administrative Science Quartely, 45(3), 425-455.

Aldrich, H., \&Fiol, C. M. (1994). Fools rush in? The institutional context of industry creation.Academyof Management Review, 19(4), 645-670.

Andreassi, T. (2007). Gestão da Inovação Tecnológica. São Paulo: Thomson Learning.

Ardichvili, A., Cardozo, R., \& Ray, S. (2003). A theory of entrepreneurial opportunity identification and development. Journalof Business Venturing, 18(1), 105-123.

ANPROTEC - Associação Nacional das Entidades Promotoras de Empreendimentos de Tecnologia Avançada; \&SEBRAE - Serviço Brasileiro de Apoio às Micro e Pequenas Empresas. (2002). Glossário dinâmico de termos na área de tecnópoles, parques tecnológicos e incubadoras de empresas.Brasília: Autores.

Autant-Bernard, C., Fadairo, M., \&Massard, N. (2013). Knowledge diffusion and innovation policies within the European regions: challenges based on recent empirical evidence. ResearchPolicy, 42(1), 196-210.

Baldi, M., \& Vieira, M. M. F. (2006). Fórum - Calçado do vale: imersão social e redes interorganizacionais. Revista de Administração de Empresas, 46(3), 16-27.

Bandeira-de-Mello, R. (2006). Softwares em pesquisa qualitativa. In: C. K. Godoi, R. Bandeira-de-Mello, \& A. B. Silva (Orgs.). Pesquisa qualitativa em estudos organizacionais. (pp. 429-460). São Paulo: Saraiva.

Bardin, L. (1977). Análise de conteúdo.Lisboa: Edições 70.

Bessant, J., \&Tidd, J. (2009). Inovação e Empreendedorismo. Porto Alegre: Bookman.

Binder, M. P., \&Maccari, E. A. (2013). Incubadoras de Empresas e o Desenvolvimento de Capacidades em Empresas Incubadas. Revista de Ciências da Administração, 15(35), 36-51.

Boeker, W. (1988). Organnizational origins: entrepreneurial and environmental imprinting of the time of founding. Ecological Models of Organizations, Cambridge: Ballinger.

Bruneel, J., Ratinho, T., Clarysse, B., \&Groen, A. (2012). The evolution of business incubators: comparing demand and supply of business incubation service across different incubator generations. Technovation, 32 , 110-121.

Burt, R. S. (2004). Structural holes and good ideas. American Journal of Sociology, 110(2), 1-48. 
Castilla, E. J., Hwang, H., Granovetter, E., \&Granovetter, M. (2000). Social networks in silicon valley. In: C. Lee, W. F. Miller, M. G. Hancock, \& H. S. Rowen (Eds.). The Silicon Valley Edge. (pp. 218-247). Stanford: Stanford University Press.

Cone, J. D., \& Foster, S. L. (2006).Dissertations and theses from start to finish. Washington: American PsychologicalAssociation.

Creswell, J. W. (2007). Projeto de pesquisa: métodos qualitativo, quantitativo e misto.Porto Alegre: Artmed.

Denzin, N. K., \& Lincoln, Y.S. (Org.). (1994). Handbook of Qualitative Research. London: Sage.

Eisenhardt, K. M., \&Schoonhoven, C. B. (1990). Organizational growth: linking founding team, strategy, environment, and growth among U.S. semiconductor ventures, 1978-1988. Administrative Science Quarterly, 35(1), 504-529.

Elfring, T., \&Hulsink, W. (2003a). Networks effects on entrepreneurial processes: Startups in the Dutch ICT industry 1990-2000. Anais do Annual Meeting, Regular Session on Organizational Founding, Atlanta, GA.

Elfring, T., \&Hulsink, W. (2003b, December). Networks in entrepreneurship: The case of high-technology firms. Small Business Economics, 21(4), 409.

Elfring, T., \&Hulsink, W. (2007). Networking by entrepreneurs: Patterns of tie-formation in emerging organizations. Organization Studies, 28(12), 1849-1872.

Erkama, N., \&Vaara, E. (2010). Struggles over legitimacy in global organizational restructuring: A rhetorical perspective on legitimation strategies and dynamics in a shutdown case. Organization Studies, 31(7), $813-839$.

Fontana, A., \& Frey, J. H. (1994). Interviewing: the art of science. In: N. K. Denzin, \& Y. S. Lincoln (Orgs.). Handbook of Qualitative Research.London: Sage.

Godoy, A. S. (2006). Estudo de caso qualitativo. In: C. K. Godoi, R. Bandeira-de-Mello, \& A. B. Silva (Orgs.). Pesquisa qualitativa em estudos organizacionais. (pp. 115-146). São Paulo: Saraiva.

Goldberg, A. I., Cohen, G., \&Fiegenbaum, A. (2003). Reputation building: small business strategies for successful venture development. Journal of Small Business Management, 41(2), 168-186.

Granovetter, M. (1973). The strength of weak ties.American Journal of Sociology, 78(6), 1360-1380.

Granovetter, M. (1974). Getting a job: a study of contacts and carrers. Cambrige: Harvard University Press.

Granovetter, M. (1985). Economic action and social structure: the problem of embeddedness. American journal of Sociology, 91(3), 481-510.

Granovetter, M. (1990). The old and the new economic sociology. In: R. Friedland, \& A. F. Robertson. Beyond the marketplace: rethinking economy and society. Hawthorne, N.Y.: Aldine de Gruyter.

Greve, H. R. (2007). Exploration and exploitation in product innovation.Industrial and Corporate Change, 16(5), 945-075.

Johannessen, J., Olsen, B., \& Lumpkin, G.T. (2001). Innovation as newness: what is new, how new, and new to whom? European Journal of Innovation Management, 4(1), 20-31.

Johnson, V. (2007, july). What is organizational imprinting? Cultural entrepreneurship in the founding of the Paris Opera. American Journal of Sociology,113(1), 97-127.

Kadushin, C. (2002). The motivational foundations of social networks. Social Networks, 24(1), 77-91.

Krippner, G., Granovetter, M., Block, F., Biggart, N., Beamish, T., Hsing, Y., Hart, G., Arrighi, G., Mendell, M., Hall, J., Burawoy, M., Vogel, S., O'Riain, S. (2004). Polanyi Symposium: A Conversation on embeddedness. SocioEconomic Review, 2(1), 109-135.

Lévesque, B. (2007). Contribuição da nova sociologia econômica para repensar a economia no sentido do desenvolvimento sustentável. Revista de Administração de Empresas, 47(2), 49-60.

Marquis, C. (2003). The PressureofthePast: network imprinting in intercorporatecommunities. Administrative Science Quarterly, 48, 655-689.

Martes, A. C. B., Loureiro, M. R., Abramovay, R., Serva, M., \& Serafim, M. C. (2007). Fórum - Sociologia econômica. RAE-eletrônica, 6(1), 4.

Moreira, D. A., \& Queiroz, A. C. S. (Org.). (2007). Inovação, Organizacional e Tecnológica. São Paulo: Thomson.

Nascimento, M. R., Pereira, J. A., Cenerino, A., Souza, M. C. D., Machado, D. S., Silva, L. V., \&Noveli, C. P. (2011). Redes Estratégicas para a Inovação: um estudo multicaso de incubadoras paranaenses. REBRAE, 4(1), 63-76.

Paiva, F. G., Jr., \& Almeida, L. F. L. (2010). A competência empreendedora de relacionamento mobilizando o capital social no processo de absorção de recursos. In: F. Gimenez, J. M. Ferreira, \& S. C. Ramos (Orgs.). Empreendedorismo e estratégia de empresas de pequeno porte - 3Es2Ps.(pp. 55-67). Curitiba: Champagnat.

Polanyi, K. (2000). A Grande Transformação. Rio de Janeiro: Elsevier.

Quandt, C. O. (2012). Redes de Cooperação e inovação localizada: estudo de caso de um arranjo produtivo local. Revista de Administração e Inovação, 9(1), 141-166. 
A influência das redes sociais na inovação: um estudo de caso em uma incubada do Centro Incubador Tecnológico - CIT/FUNDETEC

Reagans, R., \&MCEvily, B. (2003). Network structure and knowledge transfer: the effects of cohesion and range. Administrative Science Quartely, 48(2), 240-267.

Richardson, R. J. (2008). Pesquisa Social: métodos e técnicas. São Paulo: Atlas.

Rogers, E. M. (2003). Diffusion of Innovation. New York: Free Press.

Saari, E., \&Kallio, K. (2011). Developmental impact evaluation for facilitating learning in innovation networks. American Journal of Evaluation, 32(2), 227-245.

Sanz-Velasco, S. A. (2006).Opportunity development as a learning process for entrepreneurs. International Journal of Entrepreneurial Behavior \& Research,12(5), 251-271.

Serra, B., Serra, F. R., Ferreira, M. P., Fiates, G. G. (2011). Fatores fundamentais para o desempenho de incubadoras de base tecnológica. Revista de Administração e Inovação, 8(1), 221-247.

Shane, S. (2000). Prior knowledge and the discovery of entrepreneurial opportunities. Organization Science,11(4), 448-469.

Shane, S., \&Venkataraman, S. (2000). The promise of entrepreneurship as a field of research.Academy of Management Review,25(1), 217-226.

Steiner, P. (2006). A SociologiaEconômica. São Paulo: Atlas.

Stinchcombe, A. L. (1965). Social structure and organizations. In: J. G. March (Ed.). Handbook of Organizations. (pp. 142-193). Chicago, IL: Rand McNally \& Company.

Stuart, T., \& Sorenson, O. (2005).Social networks and entrepreneurship. In: S. Alvarez, R. Agarwal, \& O. Sorenson (Eds.). Handbook of entrepreneurship research: Disciplinary perspectives.(pp. 211-228). New York: Springer.

Suchman, M. C. (1995). Managing legitimacy: strategic and institutional approaches. The Academyof Management Review, 20(3), 571-610.

Swedberg, R. (2004). Sociologia Econômica:Hoje e Amanhã. Tempo Social, Revista de Sociologia da USP.São Paulo, 16(2), 7-34.

Swedberg, R., Himmelstrand, U., \&Brulin, G. (1987). The paradigm of economic sociology: premises and promises. TheoryandSociety, 16, 169-213.

Tidd, J., Bessant, J., \&Pavitt, K. (2008). Gestão da Inovação. Porto Alegre: Bookman.

Tomaél, M. I., Alcará, A. R., e Chiara, I. G. (2005). Das redes sociais à inovação. Ciência da Informação, 34(2), 93-104.

Uzzi, B. (1996). The sources and consequences of embeddedness for the economic performance of organizations: the network effect. American Sociological Review,61(4), 674-698.

Uzzi, B. (1997). Social structure and competition in interfirm networks: the paradox of embeddedness. Administrative Science Quarterly, 42, 35-67.

Vale, G. M. V., Wilkinson, J., \& Amâncio, R. (2008). Empreendedorismo, inovação e redes: uma nova abordagem. RAE-eletrônica, $7(1), 7$.

Wasserman, S., \& Faust, K. (1994).Social Network Analysis. New York: Cambridge University Press. 